\title{
Effects of Presentation Format and Instructions on the Ability of Persons With Intellectual Disability to Identify Faces
}

\author{
Antonio L. Manzanero ${ }^{a}$ \\ María José Contreras ${ }^{\mathrm{b}}$ \\ María Recio ${ }^{\mathrm{C}}$ \\ Alberto Alemany ${ }^{\mathrm{c}}$ \\ Almudena Martorell ${ }^{\mathrm{c}}$ \\ ${ }^{a}$ Universidad Complutense de Madrid \\ ${ }^{\mathrm{b}}$ Universidad Nacional de Educación a Distancia \\ ${ }^{\mathrm{c}}$ Fundación Carmen Pardo-Valcarce
}

\begin{abstract}
Summary
The aim of this work is to analyze the effect of presentation format and instructions on the ability of persons with intellectual disability to identify individuals they do not know and have seen only briefly. With this objective in mind, 2 groups of participants with mild to moderate intellectual disability were shown a photograph of a person and, after a distracting task, were asked to identify that person in 2 line-ups (target-absent and target-present) with 6 photographs each, where 2 types of instructions (neutral vs specific, between-subject design) and 2 presentation formats (simultaneous vs sequential, within-subject design) for the line-up photographs were used. Each participant completed 4 trials. The results showed that, generally speaking, persons with intellectual disability are capable of distinguishing the face of a person previously seen under all these conditions. There was a significantly higher incidence of false alarms, however, when the photographs were presented sequentially and when specific instructions were not given. With specific instructions designed to lessen the social desirability effect and increase motivation for the task, false alarms on the target-absent line-up were reduced. The results are discussed with a view to their applicability in legal and law enforcement contexts.
\end{abstract}

Key words: Memory, intellectual disability, identification of individuals, psychology of testimony, sequential line-up, instructions.

\section{Introduction}

It is not uncommon for persons with intellectual disability (ID) to be the victim of a crime (Goldman, 1994). A major difficulty in this type of case arises when the perpetrator to be identified is someone the victim does not know.

Studies have been conducted on the ability of persons with intellectual disability to identify individuals (Boucher and Lewis, 1992; Ericson and Isaacs, 2003; Manzanero, Recio, Alemany, and Martorell, 2011; Ternes and Yuille, 2008). For example, Ericson and Isaacs (2003), comparing adults with ID to those without ID, found that they were equal in terms of correct identifications, but there were more false alarms among those with ID and they were more likely to guess than those without ID. 
The question is what causes this deficit and whether its impact can be minimized, especially in terms of the incidence of false alarms. There are two hypotheses: 1) that it represents a problem with perceptual and/or attentional processing, and 2) that it arises from an acquiescence and social desirability effect.

Regarding the first hypothesis - that it may be an information processing issue-some research has shown that people who have certain syndromes associated with their intellectual disability (autism spectrum disorders, for example) have difficulty integrating information, which would affect their ability to process a face as a whole (Joseph y Tanaka, 2003; López, Donnelly, Hadwin y Leekam., 2004). This being the case, some persons with ID who also have these syndromes could find it easier to identify a person by facial features rather than by the person's face as a whole. However, most of the syndromes (Williams syndrome, for example) that do not appear to have this deficit (Tager-Flusberg, Plesa-Skwerer, Faja, and Joseph, 2003). In any event, intellectual disability typically involves a deficit in attentional capacity (Brown, Johnson, Peterson, Gilmore, Longui, Karmiloff-Smith, 2003; Tomporowski, 1997). For this study, the task required that subjects selectively attend to the stimuli presented, generate an image in their mind of the person in question, and compare this image with each individual in the line-up. A reduction of attention resources available during the task would affect the subject's performance.

If the problem had to do with a social desirability effect, perhaps the performance of subjects with ID could be improved by offering them a sequential rather than a simultaneous presentation format for the photographs in the line-up and by giving clear, motivating instructions that would mitigate the need for social approval.

Typically, in a law enforcement setting, the individuals in the line-up are presented simultaneously (i.e., they are all shown at once). However, experts in the psychology of testimony do not recommend this procedure (Wells, 1984, 1993) because it favors relative judgment- that is, the witness's evaluation of individuals in terms of how much they resemble what he/she remembers of the suspect, the one bearing the greatest resemblance being pointed out, in the end. To prevent relative judgments, it is recommended that the line-up be presented sequentially (one by one) so that the witness may use his/her memory to evaluate each individual's resemblance and decide whether there is enough resemblance to identify the individual. In essence, experiments conducted to compare these 2 procedures_-simultaneous presentation and sequential presentation-show fewer false identifications with sequential presentation than with 
simultaneous presentation (Steblay, Dysart, Fulero, and Lindsay, 2001), which could be related to more conservative response criteria (Meissner, Tredoux, Parker, and MacLin, 2005); it is not clear, however, whether the number of correct identifications is also affected (Lindsay and Wells, 1985; Memon and Gabbert, 2003). In a recent metaanalysis, Steblay, Dysart, and Wells (2011) analyzed the results obtained in 72 research studies on sequential vs simultaneous presentation. This review, which involved 23 different research centers and a total of 13,143 participants, showed a consistent pattern in 2 sets of results: 1) an increase in correct identifications on target-present simultaneous presentation (which would mean greater accuracy in identifying the "guilty" one when he/she is present in the line-up) and 2) a reduction in false alarms on target-absent sequential presentation (which would mean fewer erroneous identifications of innocent persons).

Research conducted on how presentation format affects persons with ID (Ternes and Yuille, 2008) shows that the sequential format may not be the most appropriate for this population because of differences between the tasks of target-absent identification and target-present identification. The type of participant has been shown to be a critical aspect that makes it difficult to generalize the results to other samplings of adults who do not have special, distinctive characteristics. A key moderating variable in the Steblay et al (2011) meta-analysis results was the age of the participants. With both elderly persons and children participating, higher error percentages were obtained. The performance of both the elderly adults and the children was worse than that of the middle-aged adult participants. Although Steblay et al (2011) did not include the intelligence variable (IQ) in their analysis, the nature of the sample influences the metaanalysis results in such a way that caution must be used in generalizing them to other populations with special characteristics, such as persons with ID. One of the objectives of this work was to analyze, in particular, the presentation format for face identification by persons with intellectual disability.

Another objective of the research we are presenting had to do with the type of instructions the participants are given for the line-up. One of the major biases we found in the identification of suspects in a line-up is related to the instructions given to the witnesses. These instructions usually make the participant think that the perpetrator of the crime is present and that the task is to discover him/her, which makes the participant more likely to point out a suspect, thereby increasing the chance of a false alarm (Malpass and Devine, 1981). For this reason, it is recommended that witnesses be given 
very clear instructions for the task and warned of the possibility that the guilty person may not be present in the line-up (Westerberg and Marsolek, 2006). In this regard, Foster, Libkuman, Schooler, and Loftus (1994) stated that biased instructions lead to an increased tendency to point out someone in the line-up so that, when the real perpetrator is absent, there are more erroneous identifications. This is why it is recommended that, when witnesses are initially asked to look at the line-up, their instructions should include an explicit warning that the guilty person may not appear in the line-up and that this warning should be given again when the witness is about to make an identification (Wells, Seelau, Rydell y Luus, 1994; Westerberg y Marsolek, 2006). It also appears that the biased instructions effect is weakened when subjects are informed of the consequences of their identification of an individual. Köhnken and Maass (1988) suggest that subjects in real-life situations use a more strict decision-making criterion and are less susceptible to biased instructions than subjects in a laboratory situation.

The following experiment was conducted to evaluate the effect of presentation format and instructions on the performance of subjects with ID when identifying an individual.

\section{Method}

Two factors were manipulated: presentation format (sequential vs simultaneous, within-subject) and instructions (neutral vs specific, between-subject). One group was given concrete instructions designed to reduce acquiescent responses, and the other group was given neutral instructions.

The study included a total of 40 participants (22 men and 18 women) with mild to moderate, non-specific intellectual disability (mean IQ of 58.6, $\mathrm{SD}=6.88$, range $=48$ $73)$, whose mean age was 30.45 years $(S D=4.93)$ who were randomly divided into 2 subgroups. The difference in IQ between the subgroups was not significant, $\mathrm{F}(1.39)=0.379, P>.05$ ( $\mathrm{IQ}=59.25, \mathrm{SD}=7.16$ for the neutral instructions condition, and $\mathrm{IQ}=57.90, \mathrm{SD}=6.69$ for the specific instructions condition). Participants were from the sheltered workshops and sheltered employment program at the Fundación Carmen Pardo-Valcarce in Madrid.

The measurements used were identification accuracy (correct identifications, false alarms, omissions, and correct rejections), discriminability index ( $\left.d^{\prime}\right)$, and response criterion (c) within the framework of Signal Detection Theory (MacMillan and Kaplan, 1985; Tanner and Swets, 1954). 


\section{Procedure}

The procedure used was adapted from the one used by Lyle and Johnson (2004). Participants, individually, were shown a photograph of a woman for 6 seconds; then, after being distracted for 1 minute with a visual search task with letters, they were shown 2 line-ups (the first, target-absent and the second, target-present) made up of 6 photographs each. Each subject participated in 4 trials-2 with simultaneous presentation and 2 with sequential presentation of the photographs in the line-upcounterbalancing the order from some subjects to others to prevent a learning effect in the results.

A visual search task with letters was chosen as the distracting task, following the paradigm initially proposed by Neisser (1963). This task, in which a letter is shown that must then be located within an array of letters, is routinely used to evaluate attentional capacity. To some extent, this task and the task of face recognition have processes in common: the participant must visually scan to select a stimulus previously presented from among an array of comparable stimuli. Therefore, performing the visual search task would serve as training for the subsequent task of identifying an individual and, with subjects of this type, would facilitate understanding of the task.

Both of these tasks were completed on a computer, using a program that randomly selects both the initial stimuli presented and, subsequently, the position of the target stimulus within the array of photographs. Participants looked at the line-ups on the screen, and it was the experimenter, using the mouse, who clicked on the response they chose so that errors stemming from their motor function problems would be minimized.

In the sequential procedure, when a photograph was identified as the target stimulus, the presentation did not stop but continued until participants had viewed all the photographs; thus, it was possible for them to make further identifications in the line-up.

The target stimulus was a full-face photograph of a young woman (about 20 years of age) dressed in black so that her clothing would not serve as a clue. The distracting photographs were of women with features similar to those in the target photographs - all of them white, dark-haired women, also dressed in black, with no special distinctive features. The distracters were chosen for their physical resemblance 
to the target photograph from among 349 file photographs of Psychology majors at the Universidad Autónoma de Madrid during the 2002-2003 school year.

The primary objective for the design of the instructions was to minimize false alarms. In all cases, the following instructions were given when the target photograph was presented: "We are going to show you a face. Look at it closely". The subjects then performed the visual search task, followed by the recognition tasks.

Before the line-ups were presented in the 2 formats (sequential and simultaneous) for the recognition test, subjects were informed of the task to be completed: "Now we are going to show you a group of faces. If you see the face you were shown at the beginning, point to it. Look at them closely. Take all the time you need, and when you are sure, say, “IT'S THIS ONE” and point to the face you mean. If you don't see the face, say, “IT'S NOT THERE.”

In the specific instructions condition, 3 other factors were also addressed: 1 ) the insecurity that results from not understanding the task very well, for which an explanation with concrete examples was formulated to help subjects understand what a line-up is; 2) social desirability, for which a detailed explanation was given of why it is important to be sure before making an identification; and 3) motivation, for which subjects were given an explanation of the importance of our research.

\section{Results}

\section{Accuracy}

Table 1 shows the mean score, standard deviation, and proportion obtained for each type of response on the target-absent and target-present line-ups and for the 2 conditions analyzed: sequential or simultaneous presentation format (within-subject) and type of instructions (between-subject).

\section{PLEASE, INSERT TABLE 1 ABOUT HERE}

The significance of differences in the means for each type of response for each design condition was analyzed using the general linear model procedure. Presentation format (with 2 values, sequential and simultaneous) was defined as an within- factor and the instructions condition (with 2 values, neutral or specific) as an between-subject factor. 
As for the primary effects of the presentation format factor, its effect was significant only in the case of the target-present line-up. There were more correct rejections with simultaneous presentation of the photographs than with sequential presentation (83.54\% vs $77.02 \%$ ), and this difference was significant, $F(1,38)=7.968$, $P<.01, \eta^{2}=.173, \mathrm{MSE}=2.386$. The difference for correct identifications was also significant $(7.92 \%$ on simultaneous vs $10.85 \%$ on sequential), $F(1,38)=5.255, P<.05$, $\eta^{2}=.121, \mathrm{MSE}=.402$. Presentation format was found to have no significant effect on either false alarms and omissions on the target-present line-up or false alarms and correct rejections on the target-absent line-up.

With regard to the instruction type factor, the results showed that the instructions had a significant effect only in the case of the target-absent line-up. There were significantly fewer false alarms when subjects were given specific instructions than when they were given neutral instructions (2.92\% vs $11.06 \%), F(1,38)=6.002, P<.05$, $\eta^{2}=.136$, MSE=3.168. There were also significantly more correct rejections with specific instructions than with neutral instructions (97.08\% vs $88.94 \%), F(1,38)=6.376$, $P<.05, \eta^{2}=.144$, MSE=3.137. No significant effects were found for the instructions factor on any of the subjects' responses on the target-present line-up.

Finally, these 2 factors were found to have a significant interaction effect for 2 types of response on the target-absent line-up: false alarms, $F(1,1,38)=4.527, P<.05$, $\eta^{2}=.106$, and correct rejections, $F(1,1,38)=4.024, P<.05 . \eta^{2}=.096$. As shown in Table 1 , the best condition for the target-absent line-up was a sequential presentation with specific instructions, and the worst condition was a sequential presentation with neutral instructions.

Table 1 also shows the $r$ index for calculating effect size for the presentation format (Cohen, 1988). As Steblay et al (2011) have indicated, one advantage of the $r$ index is that it allows the difference between the groups to be approximated in terms of percentage. Effect sizes obtained for the comparison between the sequential condition and the simultaneous condition were in the range of 0 to .34 . The greatest difference was observed in the neutral instructions condition for correct rejections with target present, where the difference between the sequential and simultaneous groups was 34\% ( $r=-.34)$, the mean for the simultaneous condition being higher. ${ }^{1}$ The least difference $(0)$

\footnotetext{
${ }^{1}$ A negative $r$ value in Table 1 indicates a higher mean score in the type of response analyzed for the simultaneous presentation, and a positive $r$ score indicates a higher mean for the sequential presentation.
} 
was in the specific instructions condition for false alarms with target present, where no differences were observed between the sequential and simultaneous formats.

\section{Discriminability and Response Criteria}

Table 2 shows the discriminability indexes $\left(d^{\prime}\right)$. The values obtained show that, generally speaking, subjects were able to discriminate target faces from filler faces under all the conditions. The contrasts in significance for $k$ signs, analyzed with the TDS-EXPER program (Reales and Ballesteros, 2006), showed that there was no significant difference between conditions in terms of discriminability $\left(X^{2}(3)=7.810\right.$, $\left.P>.05, U^{\prime}=1.677\right)$. The Figure below is a graphic representation of the degree of overlap obtained between distributions for the filler and target stimuli.

PLEASE, INSERT TABLE 2 ABOUT HERE

\section{PLEASE, INSERT FIGURE 1 ABOUT HERE}

Regarding the response criterion (c), we found that, in general, under the 4 conditions, the subjects had a marked tendency toward conservative response criteria (see Table 2: scores equal to 0 indicate a neutral criterion, greater than 0 a conservative criterion, and less than 0 a liberal criterion). The tendency to point out was greater under the neutral instructions and sequential presentation format condition, $c=0.27$. In general, more conservative response criteria were obtained with specific instructions than with neutral instructions.

\section{Discussion}

Based on the results achieved, we can state that the type of instructions affects the subjects' performance only on the target-absent line-up, depending on the line-up's presentation format. As inferred from the results, a sequential presentation requires that the witness be given specific instructions motivating him/her to perform the task properly, with verbalization of doubt permitted, and that the witness be explicitly alerted to the possibility that the person to be identified may not be present among the photographs shown; thus, it is only with good instructions that we can obtain a more conservative criterion (minimizing the acquiescence that stems from social desirability). 
A sequential presentation without proper instructions would increase the risk of error over and above the results obtained for the simultaneous condition; this is in line with the results obtained in previous research (Ternes and Yuille, 2008).

In view of these results, we recommend that simultaneous presentation be used for a line-up when the witness is a person with ID, given that he/she may not understand the bias-preventing instructions or that the instructions may not be adequate.

The question that arises from the results obtained in this study is why these participants with ID did not do better with sequential line-ups, as they did in previous studies.

In our study with persons with ID, the results obtained by Steblay et al (2011) — an increase in correct identifications on target-present simultaneous presentation and a decrease in false alarms on target-absent sequential presentation-were not duplicated across the board. As Table 1 shows, in our study, more correct identifications were obtained on target-present sequential presentation under both instructions conditions. Furthermore, on target-absent sequential presentation, false alarms decrease only when the instructions are specific; on simultaneous presentation, false alarms decrease when the instructions are neutral.

As Steblay et al (2011) have already reported the type of participant was a modulating variable in the results obtained: the performance of the elderly and the children was worse than that of the adults. The general pattern of the results obtained on that meta-analysis is assured only for samples that are middle-aged with no special, distinctive characteristics.

Other previous research on presentation format with witnesses who did not have ID are in agreement that sequential presentation minimizes false alarms and increases correct rejections by preventing relative judgments (Wells, 1984, 1993) through more conservative response criteria (Meissner et al, 2005). However, there could also be problems with a sequential line-up stemming from a serial position effect, among other causes, as Ebbesen and Flowe (2001) have argued. From the data obtained here, we can affirm that very precise instructions are required, as well-at least for witnesses with intellectual disability, because it appears that, if the photographs are presented one by one and they are asked to make a decision on each one, the possible interference effect is stronger. It could be that, if witnesses have more time to respond-6 photographs shown one by one compared to a round of 6 photographs presented simultaneously- 
there is also more time when acquiescence is a risk because the context is one in which social desirability may be a major influence.

\section{Conclusions}

The first conclusion that can be drawn from this research data is that those persons with mild to moderate ID who participated in the study were capable of distinguishing, in the line-up, the face of the person they had seen previously-contrary to the existing myths that have arisen from popular beliefs on this subject. As previous research has shown (Manzanero, Recio, Alemany, and Martorell, 2011), their performance is not up to the level of persons who do not have ID. If the task is made easier for them, however, they could probable be able to perform well enough to be viewed as competent witnesses in a legal context, and under the appropriate conditions, a person with ID could be as good (or as bad) a witness to a crime as a person who does not have ID. The ultimate objective of this research was to determine which conditions make it easier for them.

In the context of a forensic or law enforcement investigation, what do we do when a person with intellectual disability has to identify an individual from the line-up? How do we approach those especially difficult situations where contact with the suspect was very brief? This experiment was designed to answer these questions by examining the effect of the type of instructions given (neutral vs specific) and the presentation format used (simultaneous vs sequential) for the photographs.

Instructions designed to reduce the acquiescence effect had a significant effect only on target-absent line-ups (where this effect has a special influence). When the subjects were given specific instructions, correct rejections increased and false alarms decreased on both simultaneous presentation line-ups and sequential presentation lineups. This leads us to recommend that, in all cases, special attention be given to providing instructions designed to reduce the acquiescence effect.

Presentation format affected only correct identifications on target-present lineups: in comparison with sequential presentation, simultaneous presentation increased correct identifications and correct rejections; clearly, this was due more to a change in response criterion than to changes in the ability to distinguish, which is in keeping with results obtained in other studies (Meissner et al, 2005). Subjects with ID are more cautious about making an identification on simultaneous presentation than on sequential presentation but only when the suspect is present in the line-up. These results appear to 
conflict with those obtained in other studies with subjects who do not have ID, where sequential presentation line-ups are recommended. The presentation format with which persons with ID committed more false alarms was the sequential presentation without instructions. It is on this basis that we recommend that a simultaneous presentation lineup be used with persons with ID, for it is our understanding that, in the case of persons with ID, there is less concern about the relative judgment effect than about the acquiescence effect, which is intensified on sequential line-ups because the witness has to make more decisions. There could also be an attentional problem, which is appreciated with the sequential format where the task lasts somewhat longer and requires greater sustained attention.

The results of this study support the recommendation of McQuiston-Surrett, Malpass, and Tredoux (2006): bearing in mind that this type of research has implications for legal and law enforcement situations, it would be important not to take one or the other procedure to be better by default but rather to analyze the specific conditions under which the line-up was done, such as the participants or the type of instructions and the assurances regarding their clarity. We have shown in this study that, if it is not possible to ensure that individuals with ID receive the best instructions, a simultaneous presentation line-up would be recommended.

As Gronlund, Carlson, Daylei, and Goodsell (2009) point out, having analyzed how strong an advantage the sequential line-up offers, there is no solid evidence to justify choosing sequential presentation over simultaneous presentation. These authors conclude their work by encouraging researchers to focus their resources on analyzing issues that go beyond presentation format. According to Gronlund et al (2009), efforts should be directed toward determining what memory processes are involved in the task of face recognition. To this end, current lines of research would have to be continued until line-ups are optimized by minimizing identification errors with ID people. One precedent to be kept in mind in continuing this line of research is the results of Manzanero, López, and Contreras (2011), who showed the connection between recognition accuracy and recovery experience. According to these authors, witnesses could be asked to report the recovery experiences on which they base their recognition, which could give a good indication of accuracy.

In harmony with the suggestion of Gronlund et al (2009) regarding determination of the memory processes underlying face recognition-and now that our study has shown that the sequential procedure is not inappropriate for evaluating the 
ability of persons with ID to identify individuals-future efforts could focus on analyzing the extent to which, in this population, testimony is affected by meta-memory processes, such as the feeling-of-knowing or confidence judgments in their responses.

\section{Acknowledgements}

This work was made possible through funding and support from the Fundación MAPFRE and the Fundación Carmen Pardo-Valcarce.

\section{References}

Annaz, D.; Karmiloff-Smith, A.; Johnson, M.H., \& Thomas, M. S. C. (2009). A crosssyndrome study of the development of holistic face recognition in children with autism, Down syndrome and Williams syndrome. Journal of Experimental Child Psychology, 102, 456-486

Behrmann, M.; Avidan, G.; Leonard, G.L.; Kimchi, R.; Luna, B.; Humphreys, K., \& Minshew, N. (2006). Configural processing in autism and its relationship to face processing. Neuropsychologia, 44 , 110-129.

Boucher, J., \& Lewis, V. (1992). Unfamiliar face recognition in relatively able autistic children. Journal of Child Psychology and Psychiatry, 33, 843-859.

Brown, J.; Johnson, H.; Peterson, S.; Gilmore, R.; Longui, E., \& Karmiloff-Smith, A. (2003). Spatial representation and attention in toodlers with Williams Syndrome and Down Syndrome. Neuropsychologia, 41, 1037-1046

Clare, I. C. H. \& Gudjonsson, G. H. (1993). Interrogative suggestibility, confabulation, and acquiescence in people with mild mental retardation (mental handicap): Implications for reliability during police interrogations. British Journal of Clinical Psychology, 32, 295-301.

Cohen, J. (1988). Statistical Power Analysis for the Behavioral Sciences. Second Edition. Hillsdate, NJ: LEA.

Davies, S., Bishop, D., Manstead, A., \& Tantam, D. (1994). Face perception in children with autism and Asperger's syndrome. Journal of Child Psychology and Psychiatry, 35, 1033-1057.

Ebbesen, E.B. \& Flowe, H.D. (2002). Simultaneous v. sequential lineups: What do we really know? Retrieved December 20, 2001, from http://www.psy.ucsd.edu/ eebbesen/SimSeq.htm. 
Ericson, K. \& Isaacs, B. (2003). Eyewitness identification accuracy: A comparison of adults with and those without intellectual disabilities. Mental Retardation, 41, 3, $161-173$.

Foster, R.A.; Libkuman, T.M.; Schooler, J.W., \& Loftus, E.F. (1994). Consequentiality and eyewitness person identification. Applied Cognitive Psychology, 8, 2, 107121.

Gepner, B., De Gelder, B., \& Schonen, S. (1996). Face processing in autistics: Evidence for a generalised deficit? Child Neuropsychology, 2, 123-139.

Goldman, R. L. (1994). Children and youth with intellectual disabilities: Targets for sexual abuse. International Journal of Disability, Development and Education, 41, 89-102.

Gronlund, S.D., Carlson, C.A., Dailey, S.B., \& Goodsell, Ch.A. (2009). Robustness of the sequential lineup advantage. Journal of Experimental Psychology: Applied. $15,140-152$.

Gudjonsson, G. H., Murphy, G. H., \& Clare, I. C. H. (2000). Assessing the capacity of people with intellectual disabilities to be witnesses in court. Psychological Medicine, 30, 307-314.

Joseph, R. \& Tanaka, J. (2003). Holistic and part-based face recognition in children with autism. Journal of Child Psychology and Psychiatry, 44, 529-542.

Köhnken, G. \& Maas, A. (1988). Eyewitness testimony: False alarms or biased instructions? Journal of Applied Psychology, 73, 363-370.

Lawrence, K., Kuntsi, J., Coleman, M., Campbell, R., \& Skuse, D. (2003). Face and emotion recognition deficits in Turner syndrome: A possible role for X-linked genes in amygdala development. Neuropsychology, 17, 39-49.

Lindsay, R.C.L. \& Wells, G.L. (1985). Improving eyewitness identifications from lineups: Simultaneous versus sequential lineup presentation. Journal of Applied Psychology, 70, 556-564.

López, B., Donnelly, N., Hadwin, J. A., \& Leekam, S. R. (2004). Face processing in high-functioning adolescents with autism: Evidence for weak central coherence. Visual Cognition, 11, 676-688.

Lyle, K.B. \& Johnson, M.K. (2004). Effects of verbalization on lineup face recognition in an interpolated inspection paradigm. Applied Cognitive Psychology, 18, 393403. 
MacMillan, N.A. \& Kaplan, H.L. (1985). Detection theory analysis of group data: Estimating sensitivity from average hit and false-alarm rates. Psychological Bulletin, 98, 185-199.

Manzanero, A.L., López, B., \& Contreras, M.J. (2011). Retrieval experience as an accurate indicator of person identification in line-ups. The European Journal of Psychology Applied to Legal Context, 3 (2), 129-140.

Manzanero, A:L.; Recio, M.; Alemany, A., \& Martorell, A. (2011). Reconocimiento de caras y discapacidad intelectual (Face recognition and intellectual disability). Anuario de Psicología Jurídica, 11, 41-48.

Malpass, R. S. \& Devine, P. G. (1981). Eyewitness identification: Lineup instructions and the absence of the offender. Journal of Applied Psychology, 66, 482-489.

McQuiston-Surrett, D. E., Malpass, R. S., \& Tredoux, C. G. (2006). Sequential vs. simultaneous lineups: A review of methods, data, and theory. Psychology, Public Policy and Law, 12, 137-169.

Meissner, Ch. A.; Tredoux, C.G.; Parker, J.F., \& MacLin, O.H. (2005). Eyewitness decisions in simultaneous and sequential lineups: A dual-process signal detection theory analysis. Memory \& Cognition, 33, 5, 783-792

Memon, A. \& Gabbert, F. (2003). Unravelling the effects of a sequential lineup. Applied Cognitive Psychology, 6, 703-714.

Neisser, U. (1963). Decision time without reaction time: Experiments in visual scanning. American Journal of Psychology, 76, 376-385.

Rapley, M. \& Antaki, C (1996). A conversation analysis of the 'acquiescence' of people with learning disabilities. Journal of Community and Applied Psychology, 6, 207-227.

Reales, J.M. \& Ballesteros, S. (2006). TDS_EXPER para Windows. Un programa informático para la teoría de detección de señales. Manual de usuario (TDS_EXPER for Windows. A computer program for signal detection theory. User’s Guide). Madrid:Universitas.

Steblay, N.K, Dysart, J.E, Fulero, S., \& Lindsay, R. C. L. (2001). Eyewitness accuracy rates in sequential and simultaneous lineup presentations: A meta-analytic comparison. Law and Human Behavior, 25, 459-473.

Steblay, N.K., Dysart, J.E., \& Wells, G.L. (2011). Seventy-two tests of the sequential lineup superiority effect: a meta-analysis and policy discussion. Psychology, Public Policy, and Law, 17, 99-139 
Tager-Flusberg, H., Plesa-Skwerer, D., Faja, S., \& Joseph, R. M. (2003). People with Williams syndrome process faces holistically. Cognition, 89, 11-24.

Ternes, M. \& Yuille, J.C. (2008). Eyewitness memory and eyewitness identification performance in adults with intellectual disabilities. Journal of Applied Research in Intellectual Disabilities, 21, 519-531.

Teunisse, J. P. \& De Gelder, B. (1994). Do autistics have a generalized face processing deficit? International Journal of Neuroscience, 77, 1-10.

Wells, G.L. (1984): How adequate is human intuition for judging eyewitness memory?. In G.L. Wells \& E. Loftus (Comp): Eyewitnes testimony. Psychological perspectives (pp. 256-272). New York: Cambridge University Press.

Wells, G.L. (1993). What do we know about eyewitness identification? American Psychologist, 48, 553-571.

Wells, G.L., Seelau, E.P., Rydell, S.M., \& Luus, C.A.E. (1994). Recommendations for properly conducted lineup identification tasks. In D.F. Ross, J.D. Read y M.P. Toglia (Eds.), Adults eyewitness testimony. Current trends and developments (pp. 223-244). Nueva York: Cambridge University Press.

Westerberg, C.E. \& Marsolek, Ch.J. (2006): Do instructional warnings reduce false recognition?. Applied Cognitive Psychology, 20, 97-114.

Zhu, Q.; Song, Y.; Hu, S.; Li, X.; Tian, M.; Zhen, Z.; Dong, Q.; Kanwisher, N., \& Liu, J. (2009). Heritability of the specific cognitive ability of face perception. Current Biology, 20, 2, 137-142. 
Table 1. Mean scores, standard deviations, proportions, and effect size ( $r$ ) for each type of response on target-absent and target-present line-ups.

\begin{tabular}{|c|c|c|c|c|c|c|c|c|c|c|c|c|c|c|}
\hline & \multicolumn{7}{|c|}{ Neutral Instructions } & \multicolumn{7}{|c|}{ Specific Instructions } \\
\hline & \multicolumn{3}{|c|}{ Sequential } & \multicolumn{4}{|c|}{ Simultaneous } & \multicolumn{3}{|c|}{ Sequential } & \multicolumn{4}{|c|}{ Simultaneous } \\
\hline & $\mathrm{M}$ & SD & Ratio & $\mathrm{M}$ & SD & Ratio & $r$ & $\mathrm{M}$ & SD & Ratio & $\mathrm{M}$ & SD & Ratio & $r$ \\
\hline \multicolumn{15}{|l|}{ Target-absent line-up } \\
\hline $\begin{array}{l}\text { - Correct } \\
\text { rejections }\end{array}$ & 10.20 & 2.89 & 85.00 & 11.10 & 0.85 & 92.89 & -.20 & 11.80 & 0.41 & 98.33 & 11.50 & 0.76 & 95.83 & .24 \\
\hline - False alarms & 1.8 & 2.89 & 15.00 & 0.85 & 0.81 & 7.11 & .21 & 0.20 & 0.41 & 1.66 & 0.50 & 0.76 & 4.16 & -.23 \\
\hline \multicolumn{15}{|l|}{ Target-present line-up } \\
\hline $\begin{array}{l}\text { - Correct } \\
\text { identifications }\end{array}$ & 1.40 & 0.82 & 12.22 & 1.00 & 0.73 & 8.33 & .24 & 1.15 & 0.88 & 9.54 & 0.90 & 0.85 & 7.5 & .14 \\
\hline 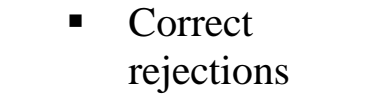 & 8.45 & 3.03 & 73.79 & 10.05 & 0.22 & 83.75 & -.34 & 9.65 & 2.25 & 80.08 & 10.00 & 0.00 & 83.33 & -.10 \\
\hline - Omissions & 0.58 & 0.77 & 4.80 & 0.60 & 0.68 & 5.00 & -.01 & 0.85 & 0.88 & 7.05 & 0.70 & 0.80 & 5.83 & .08 \\
\hline - False alarms & 1.05 & 2.31 & 9.17 & 0.35 & 0.67 & 2.92 & .20 & 0.40 & 0.68 & 3.32 & 0.40 & 0.60 & 3.33 & 0 \\
\hline
\end{tabular}


Manzanero, AL.; Contreras, M.J.; Recio, M.; Alemany, A. y Martorell, A. (2012). Effects of presentation format and instructions on the ability of people with intellectual disability to identify faces. Research in Developmental Disabilities, 33, 391-397. doi:10.1016/j.ridd.2011.09.015

Table 2. Discriminability scores $\left(d^{\prime}\right)$ and response criterion $(c)$ and their corresponding standard deviations (SD) and significance values (Z).

Neutral Instructions Specific Instructions

\begin{tabular}{|c|c|c|c|c|c|c|c|c|c|c|c|c|}
\hline & \multicolumn{3}{|c|}{ Sequential } & \multicolumn{3}{|c|}{ Simultaneous } & \multicolumn{4}{|c|}{ Sequential } & \multicolumn{2}{|c|}{ Simultaneous } \\
\hline & & SD & Z & & SD & $Z$ & & SD & Z & & SD & $Z$ \\
\hline$d^{\prime}$ & 1.69 & .23 & $7.465 *$ & 1.93 & .25 & $7.846^{*}$ & 2.11 & .23 & 9.005* & 1.91 & .25 & $7.714^{*}$ \\
\hline C & 0.27 & .11 & $2.373 *$ & 0.65 & .12 & $5.251^{*}$ & 0.87 & .12 & 7.393* & 0.80 & .12 & $6.441^{*}$ \\
\hline
\end{tabular}

* Significant $(P<.05)$ 


\section{FIGURE CAPTION.}

Figure. Graphic representation of the overlap between filler (new face) and target stimulus (face previously seen) distributions for the different conditions: 1) sequential presentation with neutral instructions; 2) simultaneous presentation with neutral instructions; 3) sequential presentation with specific instructions; and 4) simultaneous presentation with specific instructions.

\section{Figure}
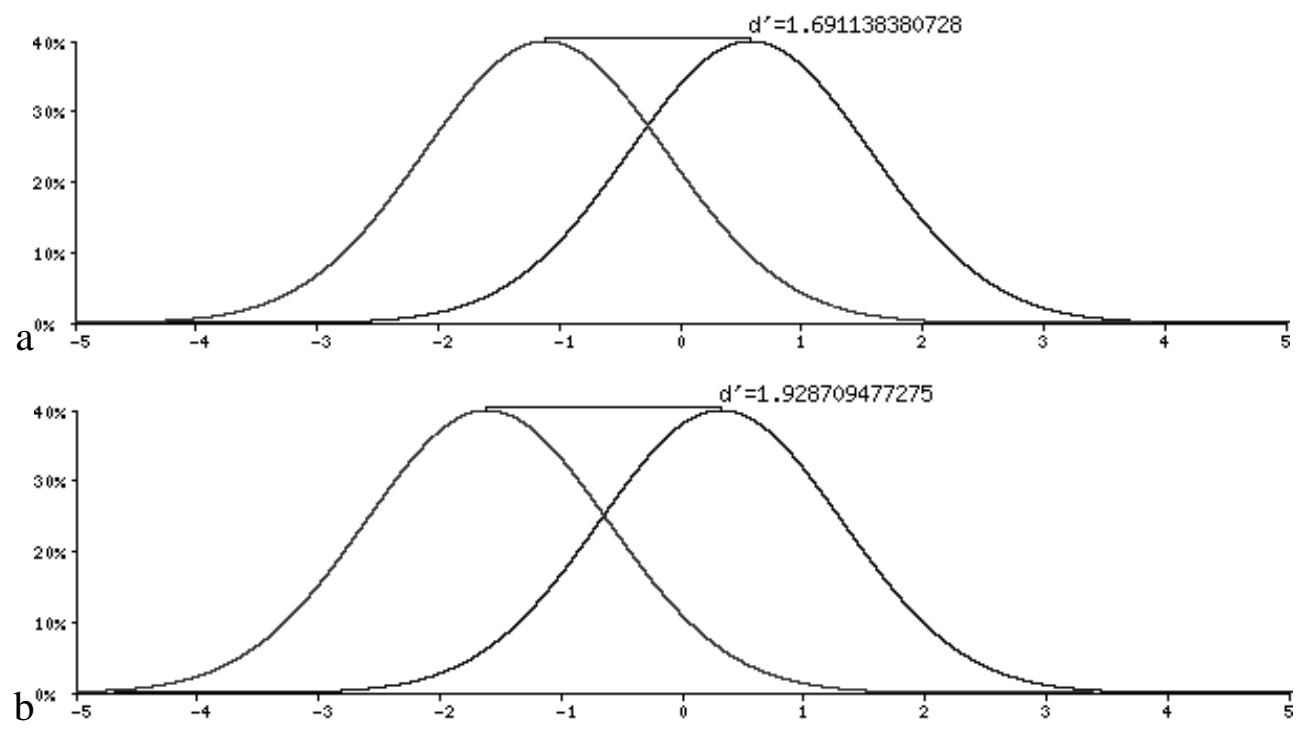

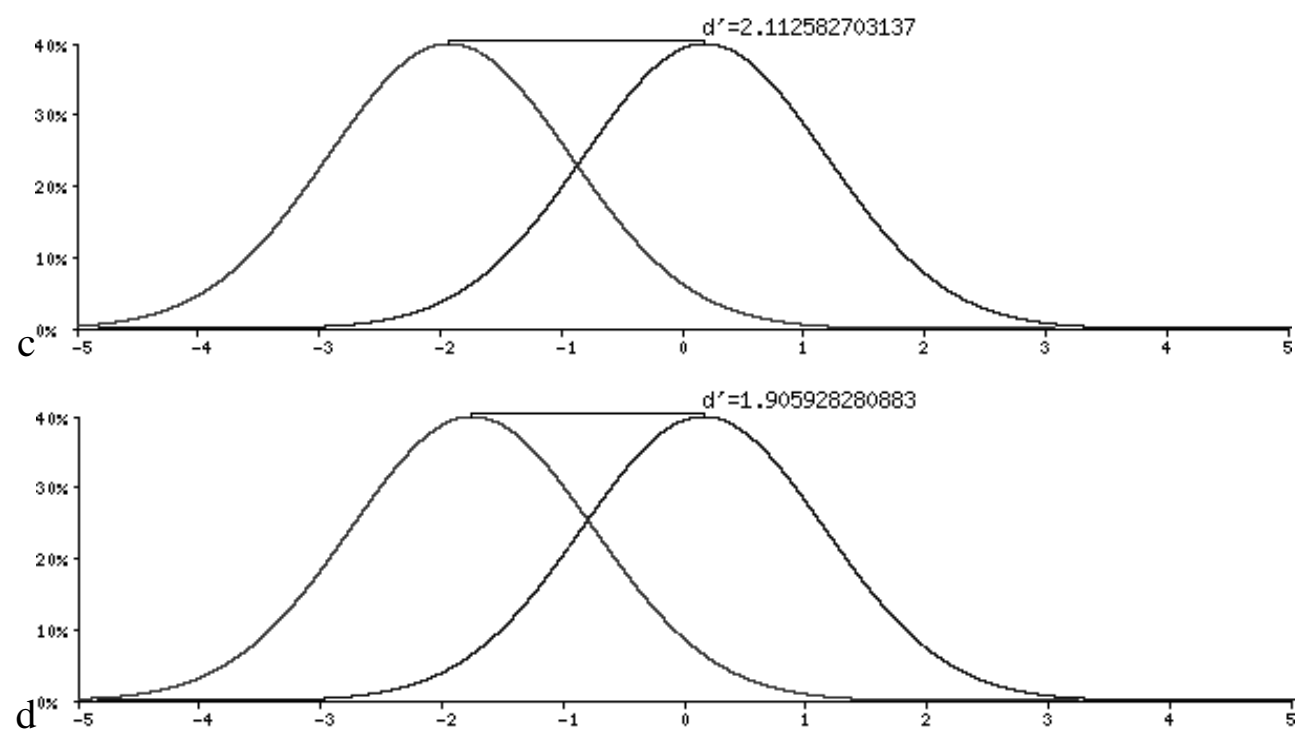